\title{
Open reduction in neglected elbow dislocation in children: a case series
}

\author{
Komang Agung Irianto*, Raymond Parung**, and William Putera Sukmajaya***
}

\section{ABSTRACT}

\section{BACKGROUND}

Elbow deformity in children due to neglected proper fracture management is a devastating condition. The stiffness and pain complicated the function in daily activity. Successful management of neglected elbow dislocation is a challenging problem for orthopedic surgeons. In this study, we aimed to evaluate results of open reduction for neglected elbow dislocation in children.

\section{CASE DESCRIPTION}

This is a case series of 13-14 years old neglected elbow dislocations, for up to 15 months. Open reduction after external distractor and followed by intensive rehabilitation was implemented. Clinical and functional outcome were evaluated within 4-7 years. Initial average elbow flexion was 53, $3^{\circ}$, extension was $0^{\circ}$, arc of flexion was $53,3^{\circ}$, arc of pronation-supination was $150^{\circ}$ and Mayo Elbow Performance Index (MEPI) was 80. Clinical and functional outcome were evaluated within 4-7 years. At follow-up after open reduction, the improvement in whole range of movement was significant. Average elbow flexion was $118,3^{\circ}$, extension was $36,67^{\circ}$, arc of flexion was $81,67^{\circ}$, arc of pronation-supination was $133^{\circ}$. The average improvement of flexion was $65^{\circ}$, arc of flexion was $31,67^{\circ}$, and arc of pronation-supination was $8,3^{\circ}$. The average loss of flexion was $15,5 \%$, arc of flexion was $44,2 \%$, and arc of pronation-supination was $10,7 \%$ compared with uninjured side. The average Mayo Elbow Performance Index (MEPI) was 96,67; all with excellent results.

\section{CONCLUSION}

Planned and well execution open reduction in pediatric neglected elbow dislocation may bring back the painless movement within normal daily function.

Keywords: Neglected, elbow dislocation, children, open reduction
*Dr. Soetomo General Hospital, Department of Orthopedic and Traumatology, Medical Faculty, Airlangga University, Surabaya, Indonesia

**Resident, Dr. Soetomo General Hospital, Department of Orthopedic and Traumatology, Medical Faculty, Airlangga University, Surabaya, Indonesia

***Jombang General Hospital, Internship Doctor

\section{Correspondence:}

Komang Agung Irianto

Dr. Soetomo General Hospital, Department of Orthopaedic and Traumatology, Medical Faculty, Airlangga University Jalan Mayjend Prof. Dr. Moestopo 68 Surabaya, Indonesia Phone: +6231 5501481 Email: komang168@yahoo.com ORCID ID: 0000-0001-6625970X

Date of first submission, October 5 , 2018

Date of final revised submission, January 29, 2019

Date of acceptance, January 30, 2019

This open access article is distributed under a Creative Commons AttributionNon Commercial-Share Alike 4.0 International License

Cite this article as: Irianto KA, Parung R, Sukmajaya WP. Open reduction in neglected elbow dislocation in children: a case series. Univ Med 2019;38:63-8. doi: 10.18051 /UnivMed.2018.v38.6368 


\section{INTRODUCTION}

Pediatric elbow deformity mostly caused by unreduced dislocation following neglected proper fracture management. ${ }^{(1-3)}$ Fracture around elbow, especially in children, often caused by fall (domestic, school, playground), not by traffic accident; ${ }^{(4-6)}$ this is the main reason why usually they were taken to bonesetter and not to hospital. ${ }^{(7,8)}$ Unfortunately, this type of fracture often associated with elbow dislocation which practically fail to be reduced in incompetent hand. ${ }^{(9,10)}$

Neglected elbow dislocation limit the range of motion (ROM) especially the flexion to nearly $0 \circ-50$; the patients could not function their hand for simple daily function (comb, button, feed) or fine motoric (writing). ${ }^{(10-12)}$ Open reduction is a good choice of management even when the unreduced joint was untreated for more than three weeks. ${ }^{(7,10,11)}$ Several reported cases of several months up to two years elbow neglected dislocation were successfully treated. (7,8,12) $^{(1)}$ However, in pediatric where the open physes is the issue, the precondition and intense post rehabilitation should be considered. We report three cases of neglected pediatric elbow dislocation treated by external distractor to precondition the soft tissue, open reduction with or without V-Y plasty triceps lengthening, Kwire stabilization, cast, and intense 6 weeks post-surgery rehabilitation.

The Mayo Elbow Performance Index (MEPI) ${ }^{(13)}$ was used to evaluate the subjective, objective, and functional characteristics prior to the surgery and at follow-up. This scoring system has four parameters: pain, motion, stability, and performance of five activities of daily living (comb, feed, personal hygiene, put on shirt, and shoe (Table 1). Stability of the elbow is rated as stable (no apparent varus/valgus instability), moderate instability $\left(<10^{\circ}\right.$ varus/valgus instability), or gross instability $\left(\geq 10^{\circ}\right.$ varus/valgus instability). Depending on the score, the MEPI was classified as excellent (90-100), good (75$89)$, fair (60-74), or poor $(<60)$.
Table 1. Mayo Elbow Performance Index (MEPI) ${ }^{(2)}$

\begin{tabular}{|c|c|c|}
\hline Function & Points & Definition (Points) \\
\hline Pain & 45 & $\begin{array}{c}\text { None }(45) \\
\text { Mild }(30) \\
\text { Moderate }(15) \\
\text { Severe }(0)\end{array}$ \\
\hline Motion & 20 & $\begin{array}{c}\operatorname{Arc}>100^{\circ}(20) \\
\operatorname{Arc} 50^{\circ}-100^{\circ}(15) \\
\operatorname{Arc}<50^{\circ}(5)\end{array}$ \\
\hline Stability & 10 & $\begin{array}{c}\text { Stable (10) } \\
\text { Moderate instability (5) } \\
\text { Gross instability (0) }\end{array}$ \\
\hline Function & 25 & $\begin{array}{c}\text { Comb hair (5) } \\
\text { Feed (5) } \\
\text { Perform hygiene (5) } \\
\text { Don shirt (5) } \\
\text { Don shoe (5) }\end{array}$ \\
\hline Total & 100 & $\begin{array}{l}\text { Excellent }>90 \text {; good: } 75-89 \text {; } \\
\text { fair: } 60-74 \text {; poor }<60\end{array}$ \\
\hline
\end{tabular}

\section{CASE PRESENTATION}

The research protocol of this case series was approved by institutional ethics and review board in Dr. Soetomo General Hospital. We report three cases of pediatric neglected elbow dislocation whom underwent open reduction in Dr. Soetomo General Hospital during January 2012- May 2014. The age of patients was 11,14 , and 14 years old. In all cases, the mode of injury was fall with outstretched hand. All patients were presented with the history of bone-setter treatment in the form of massage or manipulation and immobilization for up to fifteen months. Elbow stiffness in extension and pain were the principal indication for surgical treatment. The range of motion of flexion, extension, pronation, and supination were examined with a handheld goniometer. Patient 2 (Figure 1) and patient 3 has associated lateral condyle fracture.

The initial average elbow flexion was $53,3^{\circ}$ $\left(90^{\circ}, 20^{\circ}\right.$, and $\left.50^{\circ}\right)$. The average of arm rotation (arc of pronation-supination) was $150^{\circ}\left(130^{\circ}\right.$, $160^{\circ}$, and $\left.160^{\circ}\right)$; pronation being more limited than supination; and average of MEPI was 80 $(85,65$, and 90$)$. The deformity itself did not trouble all male patients but the pain in trying to 

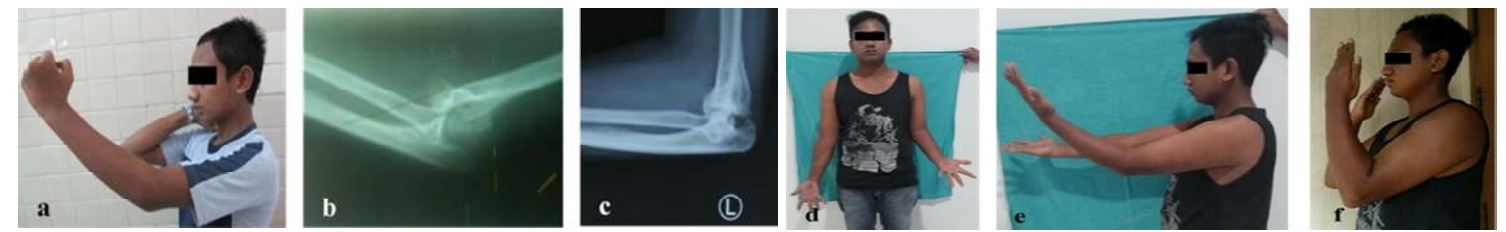

A patient 14-year-old boy with 4-month-old unreduced complex dislocation of the left elbow: (a) preoperative clinical presentation, (b) Lateral view preoperative showing complex dislocation of the left elbow. (c) Lateral view postoperative at 6-years follow-up (d), (e), and (f) at 6 years follow-up, the patient has optimum range of movement of the left elbow and has no difficulty in performing functional task for activities of daily living

do their daily activity is the main reason to seek for surgical correction. Patient 2 got the complication of ulnar numbness and the MEPI was worst (65) (Table 2).

Prior to surgery all patients were put on external distractor for at least 2 weeks, to stretch the soft tissues slowly to achieve easier reduction during surgery. Elbow distraction was performed until ulno-humeral joint were in the same level, where the triceps contracture were gradually loosen and no longer resist and pin down the joint. Open reduction was performed with or without VY-plasty of triceps lengthening depend on the success perseverance of the distraction. The intraoperative findings of the fibrosis and calcification of the soft tissue determine the further surgical expansion. Patient 1 did not need triceps lengthening. But they all need K-wire stabilization and cast afterward. K-wire was extracted after 2 weeks. Patient 2 need ulnar nerve transposition to release the trapped nerve. The nerve fibrosis was not severe.

Rehabilitation was carried soon after Kwire removal and wound healed. Intensive rehabilitation physiotherapy was maintained for 6 weeks. None of patients got post-surgery skin infection.

Clinical and functional outcome of all three patients (MEPI) were evaluated after 4 years to 6 years. All patients were satisfied and could perform functional range of motion for daily activity (MEPI average 96.67; excellent) although deformity is not fully corrected. All three patients showed none of any sign of instability (score:10), pain free (score: 45), and able in most of five activities of daily living. The average elbow flexion was $118,3^{\circ}$ (range $110^{\circ}$ $125^{\circ}$ ), arc of flexion was $81,67^{\circ}$ (range $70^{\circ}$ $105^{\circ}$ ), arc of pronation-supination was $156.67^{\circ}$ (range $145^{\circ}-170^{\circ}$ ).

The improvement in the whole range of movement was very well. Nonetheless, compared to the uninjured side, the average loss of flexion was still 15,5\% (range $10.7 \%-18.5 \%$ ), arc of flexion was $44,2 \%$ (range, $27.58 \%-$ $53.3 \%)$. Patient 1 regained functional range of movements and two other patients regained optimum range of movements (Table 2). Hypoesthesia of the hand over the ulnar nerve distribution without appreciable motor weakness was still present in patient 2. All patients in this study had no trouble in performing functional task.

\section{DISCUSSION}

For the patients, cosmetic is not the major concern, but the limitation of function is. Not only that it is predictable and could be avoided, it also decreases the child's self-esteem and quality of life when they could not function normal in daily activity especially for personal hygiene. Patient 1 came with flexion $0^{0}-90^{\circ}$ after treatment gain almost full flexion into $5^{0}-$ $110^{\circ}\left(105^{\circ}\right.$ arc of flexion). He gains a perfect function and good cosmetic as well and he was very satisfied with MEPI score 100 . But patient 2 and 3 still deform (flexion $50^{\circ}$ and $55^{\circ}$ ), not a cosmetic but functionally they gain a lot $\left(120^{\circ}\right.$ and $125^{\circ}$ ). The biomechanical study of normal functional elbow motion from Mayo clinic notion $130^{\circ}$ flexion as the normal functioning range of motion where a person could reach the occiput, to comb, to feed, doing personal hygiene, and 
Table 2. Data before and after open reduction for neglected pediatric elbow dislocation

\begin{tabular}{|c|c|c|c|}
\hline & Patient 1 & Patient 2 & Patient 3 \\
\hline Gender & male & male & male \\
\hline Age (years) & 14 & 14 & 11 \\
\hline Mode of injury & Fall & Fall & Fall \\
\hline Injured side & Left & Left & Right \\
\hline First treatment at & Bonesetter & Bonesetter & Bonesetter \\
\hline Time of neglected & 5 months & 4 months & 15 months \\
\hline Associated fracture & None & Lateral condyle & Lateral condyle \\
\hline Associated lesion & none & Ulnar palsy & none \\
\hline \multicolumn{4}{|l|}{ Treatment: } \\
\hline Elbow distraction & Yes & Yes & Yes \\
\hline Open reduction & Yes & Yes & Yes \\
\hline K-wire stabilization & Yes & Yes & Yes \\
\hline Ulnar transposition & No & Yes & No \\
\hline Triceps lengthening & No & No & Yes \\
\hline Cast & Yes & Yes & Yes \\
\hline Rehabilitation & Yes & Yes & Yes \\
\hline Surgery complication & None & None & None \\
\hline Follow-up time & 4 years & 6 years & 5 years \\
\hline \multicolumn{4}{|l|}{ Uninjured elbow: } \\
\hline Flexion & $145^{0}\left(-10^{0}-135^{0}\right)$ & $145^{0}\left(0^{0}-145^{0}\right)$ & $150^{0}\left(-10^{0}-140^{0}\right)$ \\
\hline Pronation/supination & $170^{\circ}\left(85^{0}-85^{0}\right)$ & $180^{\circ}\left(90^{\circ}-90^{\circ}\right)$ & $165^{0}\left(75^{0}-90^{0}\right)$ \\
\hline \multicolumn{4}{|l|}{ Injured elbow; before: } \\
\hline Flexion & $90^{0}\left(0^{0}-90^{0}\right)$ & $20^{0}\left(0^{0}-20^{0}\right)$ & $50^{0}\left(0^{0}-50^{0}\right)$ \\
\hline Pronation/supination & $130^{0}\left(50^{0}-80^{0}\right)$ & $160^{\circ}\left(80^{\circ}-80^{0}\right)$ & $160^{0}\left(75^{0}-85^{0}\right)$ \\
\hline \multicolumn{4}{|l|}{ Injured elbow; on follow-up } \\
\hline Flexion & $105^{0}\left(5^{0}-110^{0}\right)$ & $70^{0}\left(50^{0}-120^{0}\right)$ & $70^{0}\left(55^{0}-125^{0}\right)$ \\
\hline Pronation/supination & $145^{0}\left(60^{0}-85^{0}\right)$ & $170^{0}\left(85^{0}-85^{0}\right)$ & $155^{0}\left(70^{0}-85^{0}\right)$ \\
\hline MEPI before / after & $85 / 100$ & $65 / 95$ & $90 / 95$ \\
\hline
\end{tabular}

tie his shoe. ${ }^{(10)}$ Some of the activities need less flexion arc since there are compensatory motion of adjacent joints. For example, while tying the shoe, they flex the hip.

Regardless duration of neglected, regardless the age of the patient, open reduction offers better motion, better stabilisation for function. Case reports and new surgical approach showed good to excellent result. ${ }^{(14)}$ But if there are associated fracture around the elbow, the outcome of the open reduction is not satisfying. ${ }^{(9,15,16)}$ In our cases, patient 2 and 3 with associated lateral condyle fracture, complicating the soft tissue fibrosis, not the alignment of fracture healing. That is the reason for VY plasty triceps muscle lengthening.

The contracture of the triceps muscle locks the joint and limit the motion, conversely triceps muscle need to be loosen. More than three decades ago when surgeon reluctant to operate neglected elbow dislocation especially in children, conservative external fixator (hinged elbow distraction device) were applied for 6-8 weeks to gradually reconstruct. This technique was not advocate anymore owe to high failure outcome. ${ }^{(8)}$ In our protocol of treatment, we use external distractor for 2 weeks to gradually distract the soft tissue responsible for the contracture. We used the device as adjunct to open reduction. Other reports the similar way prior to surgical reduction either with or without triceps muscle lengthening. ${ }^{(9,12-14)}$ Anderson et al. ${ }^{(9)}$ develop new technique of triceps lengthening without VY plasty, by repeated piercing the tendon percutaneous with $18 \mathrm{G}$ needle, only for selected case for simple dislocation and without associated fracture.

Kirschner wire was placed to stabilized and the cast was applied for 2 weeks to allow early rehabilitation which is very important to maintain the reduced joint and avoid further contraction. $(12,15,16)$ The two weeks period was also the reason to prevent skin infection. In our report, none of the patients have skin infection. The 
other technique to stabilize the reduced joint was reported in India by Garg et al. ${ }^{(17)}$ by adding cruciate ligament like from semitendinous autologous graft. Excellent MEPI result was achieved.

Almost all authors in the last decades advice an earlier rehabilitation for excellent result disregarding the period of unreduced elbow. ${ }^{(4,18,19)}$ Although all our patients accomplished similar intense rehabilitation, only patient 1 without VY plasty triceps muscle avoid futher contracture (excellent result). Patient 2 and 3 managed to benefit enough ROM for functional goal and that goal is enough for the patient render the poor cosmetic.

\section{CONCLUSIONS}

Open reduction is a necessity for neglected elbow dislocation in children regardless of the time of the injury. The outcome of the treatment is to gain enough ROM for useful hand to achieve painless daily activity.

\section{CONFLICT OF INTEREST}

The authors declared no competing and conflict of interests.

\section{ACKNOWLEDGMENTS}

We thank and acknowledge the contribution of all patients involved in this study.

\section{CONTRIBUTORS}

KAP contributed to study concept, design and drafting manuscript. RP contributed to acquisition of data. WPS contributed to critical revision of the manuscript. All authors have read and approved the final manuscript.

\section{REFERENCES}

1. Herring JA, Ho C. Upper extremity injury. In: Herring JA, editor. Tachdjian's pediatric orthopaedics: from The Texas Scottish Rite
Hospital for Children. $5^{\text {th }}$ ed. Philadelphia: Elsevier Saunders; 2014.p.1264-319.

2. Mahaisavariya B. Neglected dislocation of the elbow. In: Jain AK, Kumar S, editors. Neglected musculoskeletal injuries. $1^{\text {st }}$ ed. New Delhi: Jaypee Brothers Medical Publishers (P) Ltd;2010.p.31825.

3. Mehta S, Sud A, Tiwari A, et al. Open reduction for late-presenting posterior dislocation of the elbow. J Orthop Surg (Hong Kong) 2007;15:1521.

4. Ivo R, Mader K, Dargel J, et al. Treatment of chronically unreduced complex dislocations of the elbow. Strat Traum Limb Recon 2009;4:49-55. doi: 10.1007/s11751-009-0064-1.

5. Elzohairy MM. Neglected posterior dislocation of the elbow. Injury 2009;40:197-200. doi: 10.1016/ j.injury.2008.05.034.

6. O'Driscoll SW. Elbow dislocations. In: Morrey BF, Sanchez-Sotelo J, editors. The Elbow and its disorders. $4^{\text {th }}$ ed. Philadelphia: W.B. Saunders Co.;2008.p.436-49.

7. Islam MS, Jahangir J, Manzur RM, et al. Management of neglected elbow dislocations in a setting with low clinical resources. Orthop Surg 2012;4:177-81. doi: 10.1111/j.1757-7861.2012. 00190.x.

8. Lyons RP, Armstrong A. Chronically unreduced elbow dislocations. Hand Clin 2008;24:91-103. doi: 10.1016/j.hcl.2007.11.008.

9. Anderson RD, Haller JM, Anderson LA, et al. Surgical treatment of chronic elbow dislocation allowing for early range of motion: operative technique and clinical results. J Orthop Trauma 2017;32:1-8. doi: 10.1097/BOT.0000000000001097.

10. Fornalski S, Gupta R, Lee TQ. Anatomy and biomechanics of the elbow joint. Tech Hand Up Extrem Sur 2003;7:168-78.

11. Morrey BF, An KN. Functional evaluation of the elbow. In: Morrey BF, Sanchez-Sotelo J, editors. The elbow and its disorders. $4^{\text {th }}$ ed. Philadelphia: W.B. Saunders Co;2008.p.80-91.

12. Donohue KW, Mehlhoff TL. Chronic elbow dislocation: evaluation and management. J Am Acad Orthop Surg 2016; 24:413-23. doi: 10.5435/ JAAOS-D-14-00460.

13. Morrey BF. Chronic unreduced elbow dislocation. In: Morrey BF, Sanchez-Sotelo J, editors. The elbow and its disorders. $4^{\text {th }}$ ed. Philadelphia: W.B. Saunders Co.; 2008.p.463-71

14. Coulibaly NF, Tiemdjoa H, Sanea AD, et al. Posterior approach for surgical treatment of neglected elbow dislocation. Orthop Traumatol Surg Res 2012; 98:552-8. doi: 10.1016/j.otsr.2012. 03.006 . 
15. Kapukaya A, Ucar BY, Gem M. Open reduction and Kirschner wire fixation with triceps lengthening for neglected elbow dislocations. J Orthop Surg 2013;21:178-81.

16. Kachnerkar NI, Lakde N, Salokhe S. Neglected old posterior dislocation of elbow: treatment and results of open reduction. Int J Orthop Sci 2017; 3:1062-6. DOI: https://doi.org/10.22271/ortho. 2017.v3.i3o.154.

17. Garg P, Paik S, Sahoo S, et al. A new technique for surgical management of old unreduced elbow dislocations: results and analysis. J Orthop Allied Sci 2014; 2:45-51. doi: 10.4103/2319-2585.145599.
18. Kembhavi RS, James B, Sugirtharaj J, et al. Old unreduced posteromedial elbow dislocation: a rare case report. Webmed Central Orthopaedics 2015;6:WMC004823.

19. Maru ND, Sayani K, Ramesh. A rare case of pediatric neglected elbow dislocation treated with speed procedure. Gujarat Med J 2015;70:103-4. 